This item was submitted to Loughborough's Research Repository by the author.

Items in Figshare are protected by copyright, with all rights reserved, unless otherwise indicated.

\title{
Effective telephone triage methods
}

PLEASE CITE THE PUBLISHED VERSION

https://doi.org/10.12968/prma.2017.27.6.20

PUBLISHER

(C) MA Healthcare

VERSION

AM (Accepted Manuscript)

\section{PUBLISHER STATEMENT}

This work is made available according to the conditions of the Creative Commons Attribution-NonCommercialNoDerivatives 4.0 International (CC BY-NC-ND 4.0) licence. Full details of this licence are available at: https://creativecommons.org/licenses/by-nc-nd/4.0/

\section{LICENCE}

CC BY-NC-ND 4.0

\section{REPOSITORY RECORD}

Sikveland, Rein, and Elizabeth Stokoe. 2019. "Effective Telephone Triage Methods". figshare. https://hdl.handle.net/2134/26626. 


\section{PUBLISHED: Sikveland, R.O., \& Stokoe, E. (2017). Effective telephone triage methods. Practice Management, 27 (6), 20-22.}

\section{How receptionists handle patients' requests for appointments: Research findings for practice}

Dr Rein Ove Sikveland (Research Associate, Dept. of Social Sciences, Loughborough University, $U K$ )

Prof Elizabeth Stokoe (Professor of Social Interaction, Dept. of Social Sciences, Loughborough University, UK)

\section{Introduction}

GP receptionists are central to patients' experiences of their GP surgery, as well as access to primary care. Yet, there is surprisingly little research on telephone calls between receptionists and patients. Issues of 'experience' and 'satisfaction' are routinely addressed using surveys or focus groups and interviews. [2] The disadvantage of such methods is that they do not tell us what and how problems occur in actual patient-healthcare provider encounters. For example, while surveys may show that the 'helpfulness' of the receptionist is an important driver for satisfaction amongst UK patients, [1] we know little about what constitutes such helpfulness. Based on conversation analysis [3], we identify more, and less, effective practice in terms of how receptionists interact with patients. Our research underpins receptionist training in the UK, based on the Conversation Analytic Role-play Method (CARM: www.carmtraining.org), [4] where we show what needs to change in order to improve patient experience regarding access to their GP.

In this article we report on two studies we have undertaken, on telephone calls from patients to three different GP surgeries in the UK. First we show that receptionists can, with simple means, increase or decrease the 'burden' on patients to get service at the GP surgery. Second, we show how receptionists, by listening to how patients formulate their inquiry, may identify 
whether or not patients require an urgent appointment - without having to ask what the appointment is for and/or whether it's urgent. Based on these studies we show how receptionists can drive the telephone call forwards, both to their own, and patients', advantage.

\section{Patients expect receptionists to drive the conversation forwards}

In our first study we identified cases where the patient makes additional efforts to get service: what we call instances of service 'burden'. We identified such 'burden' in different phases of the telephone calls. [5] The first phase is soon after the opening of the call, in which the patient's request for an appointment was not met by receptionist.

Below is an illustrative example, where the patient $(\mathrm{P})$ phones to book a doctor's appointment.

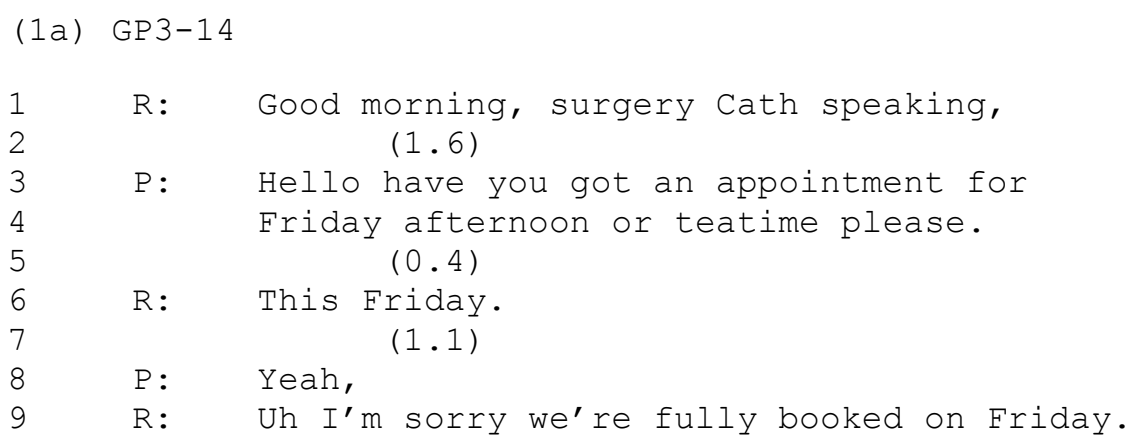

In a CARM workshop participants live through conversations without knowing what is coming next, and then "role-play" what they might do next to handle the situation. [4] In this case, at the point where the receptionist $(\mathrm{R})$ indicates that there are no available appointments on the requested day (line 9), we ask the workshop participants: What does the patient, and receptionist, expect to happen next? - Not only do we as analysts, and workshop participants, expect the receptionist to offer an alternative, but, as we will see in what follows, the patient does so too:

(1b) GP3-14

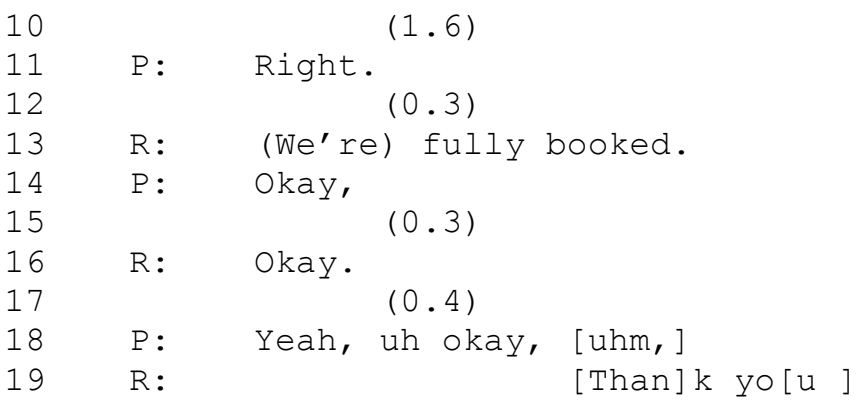


After a silence gap of 1.6 seconds (which is a very long time in conversations!), $\mathrm{P}$ shows that they are not ready to finish the conversation ("Right.", line 11). R reiterates that they are fully booked (line 13), and moves to close the call ("Okay" and "thank you", lines 16, 19). But P is reluctant to close (line 18): she pushes back into the call in lines 20-21, overlapping the end of R's turn, to ask if it is worth calling the sister surgery. In other words, rather than $\mathrm{R}$ offering an alternative course of action, the burden is on $\mathrm{P}$ to keep the call going and push for service. This kind of patient burden was common across the dataset, however, more effective receptionists made immediate alternative offers when the patient's first request could not be met, such as 'do you want me to book you in next week?'.

Importantly, it also turns out that the amount of 'burden' there is in a GP service correlates with patient satisfaction scores. Based on satisfactions scores from the GP patient survey for the three surgeries (https://gp-patient.co.uk), we found that the surgeries with more 'burden' had lower patient satisfaction scores - we focussed on two items: "X\% describe their experience of making an appointment as good" and " $\mathrm{X} \%$ find the receptionist at this surgery helpful". (Figure 1). This means that we have not only identified that there is a difference in patient satisfaction for different surgeries, but we can also suggest what makes the difference in satisfaction.

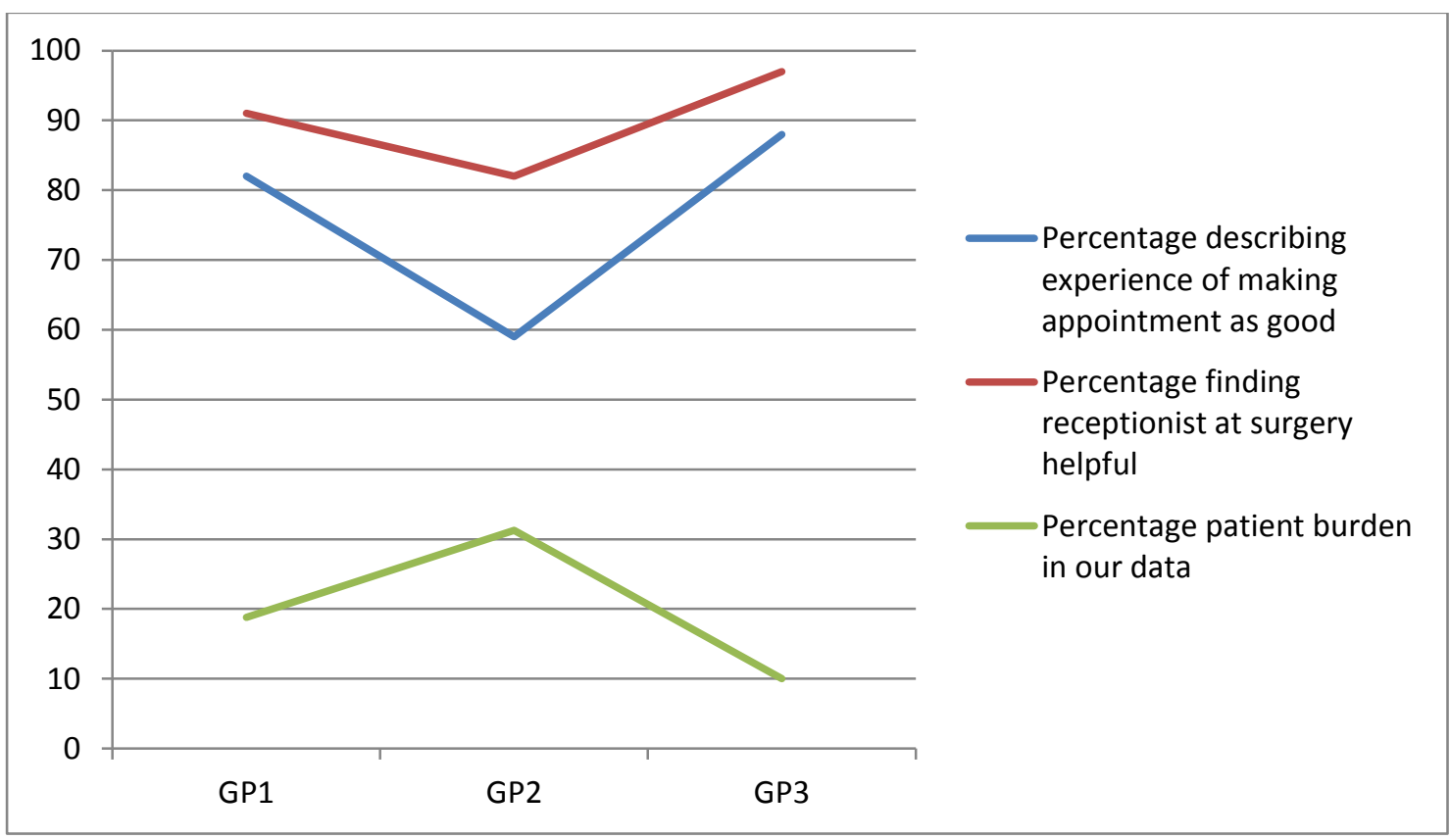

Figure 1. Satisfaction scores from the GP patient survey, for three surgeries, compared with 'patient burden'. 


\section{How to negotiate urgency effectively}

In line with the principle of triaging, receptionists seek to establish whether the patient's medical needs require a same-day appointment with a doctor (or a call-back from a doctor or nurse), or, if not urgent, whether to offer an available appointment on a future date. There are a range of different ways that receptionists can address this. In Extract 2 the receptionist asks "is it a routine appointment you're requiring":

(2) GP3 78

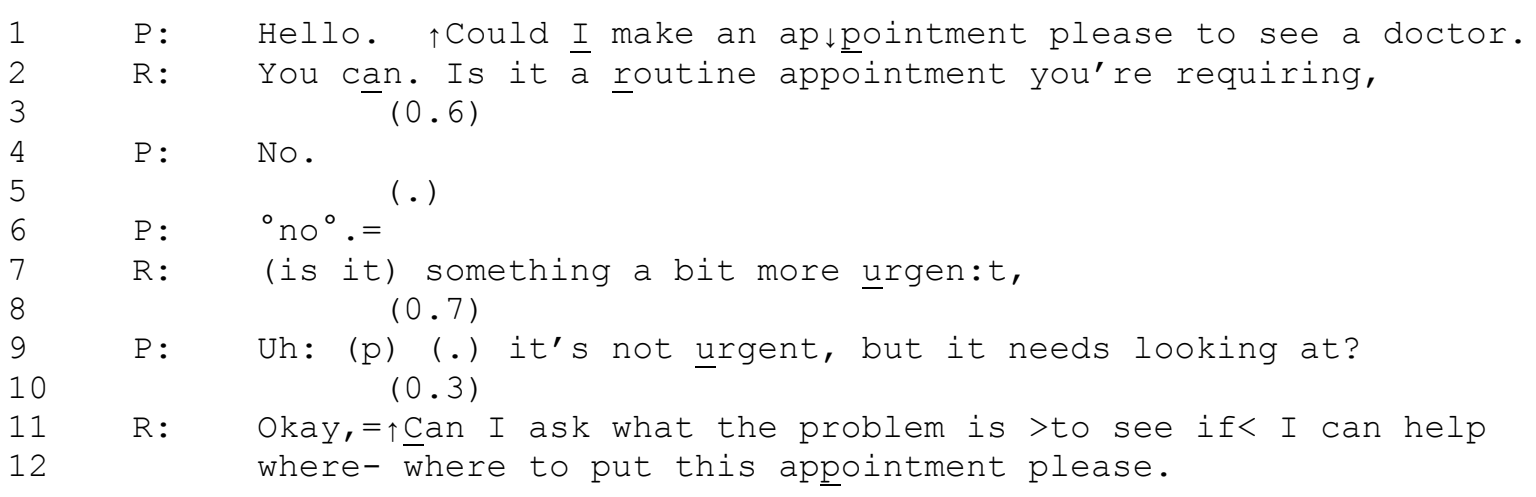

If this was an effective way of addressing the nature of the patient's enquiry, we would expect to see the conversation proceed to a relevant appointment offer next. Instead, what we found in this study was that the categories 'routine' and 'urgent' are incongruent with how the patients see their own needs. The receptionist then needs to do extra work in order to establish what kind of appointment is relevant.

It turns out that asking 'is it routine/urgent' is not productive unless the patient already indicates some kind of urgency, by asking for an appointment 'today', for example. We also found that patients who do not indicate urgency in their inquiry generally display no trouble in accepting an appointment offered several days in the future:

(3) GP2 314

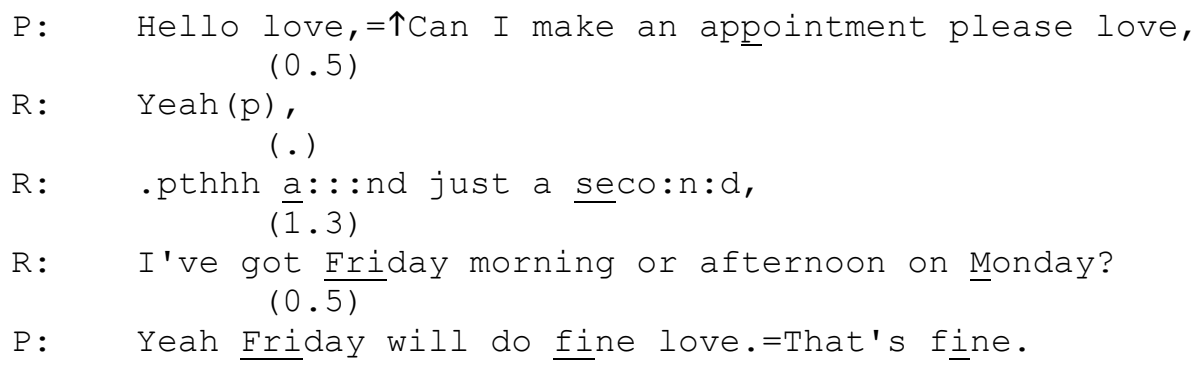


In conclusion, triage questions such as 'is it urgent?', and also 'what is it for?', are not always relevant or productive in terms of offering an appropriate appointment for the patient. Instead, our research shows that offering the next available appointment is the most effective way of responding to non-urgent patient enquiries: unless patients indicate urgency in their initial enquiry, receptionists can simply avoid the hurdle of explaining why they ask about urgency.

\section{The Conversation Analytic Role-play Method (CARM)}

Because our research-based training works with real recordings of real people, who have a real stake in the encounter they are having, CARM workshops contrast sharply with traditional role-play or simulated interaction for training and assessment of communications skills. First we select extracts from our findings about a particular practice (for instance, explaining a service), then we use animation software to play the audio and transcript synchronously. This means that workshop participants live through conversations without knowing what is coming next, and then "role-play" what they might do next to handle the situation. For example, having seen what the real receptionist actually does in the 'burden' example above, we also show a more effective call, where for example the caller burden is absent because the receptionist offers an alternative appointment or doctor. Participants see and evaluate different responses, identifying effective practice on the basis of what happens in real interaction.

Conversation analysis overturns what we think we know about talk. But it also reveals the tacit knowledge of GP receptionists (or police officers, mediators and salespeople) who manage their encounters productively. As we saw in Extract 3, the effective practice was right there all along - but it takes a conversation analyst to identify it.

\section{References}

1 Bensing J, Rimondini M, Visser A. What patients want. Patient Educ Couns. 2013;90(3):287-290.

2 Paddison, CA, Abel, GA, Roland, MO, et al. Drivers of overall satisfaction with primary care: evidence from the English General Practice Patient Survey. Health Expectations 2015; 20(5):1081-1092.

3 Drew P, Chatwin J, Collins S. Conversation analysis: a method for research into interactions between patients and healthcare professionals. Health Expectations. 2001;4(1):58-70.

4 Stokoe E. The Conversation Analytic Role-play Method ( CARM): A Method for Training Communication Skills as an Alternative to Simulated Role-play. Research on Language and Social Interaction. 2014;47(3):255-65.

5 Stokoe, Elizabeth, Rein O. Sikveland, and Jon Symonds. "Calling the GP surgery: patient burden, patient satisfaction, and implications for training." Br J Gen Pract 66.652 (2016): e779-e785. 